\title{
Avaliação técnico-gerencial do cumprimento dos requisitos de desempenho de edificação habitacional para estudantes
}

Mariana Rezende Schuab

mary.schu@hotmail.com

Centro Federal de Educação Tecnológica de Minas Gerais (CEFET-MG), Belo Horizonte, Minas Gerais, Brasil

\section{Pedro Valle Salles}

pedrovallesalles025@gmail.com

Centro Federal de Educação Tecnológica de Minas Gerais (CEFET-MG), Belo Horizonte, Minas Gerais, Brasil

\section{White José dos Santos} white.santos@demc.ufmg.br Universidade Federal de Minas Gerais (UFMG) Belo Horizonte, Minas Gerais, Brasil

Scarlet Natalie Jorge Peguero scarlet.jorge@hotmail.com

Centro Federal de Educação Tecnológica de Minas Gerais (CEFET-MG), Belo Horizonte, Minas Gerais, Brasil

\begin{abstract}
RESUMO
Essa pesquisa analisa as principais necessidades de alterações do processo construtivo, em alvenaria estrutural, antes e depois da vigência da NBR 15575, (2013). Desenvolveu-se um estudo de caso em uma obra destinada à Moradia Universitária, em Minas Gerais. A obra teve início antes da vigência dessa norma, logo seu atendimento não se aplicaria, contudo, sua execução foi realizada conforme às exigências das demais normas brasileiras aplicadas à construção civil. Através da análise dos dados coletados na visita técnica realizada, nas entrevistas realizadas com a responsável técnica e na verificação dos documentos disponibilizados pela empresa, foi averiguado que houve o atendimento a grande parte dos requisitos normativos. A partir das informações e constatações identificadas, formularam-se proposições de procedimentos necessários à validação do nível desempenho atendido pela edificação. O presente estudo de caso demonstrou que, ainda sem a obrigatoriedade do atendimento à norma de desempenho, é possível estar conforme a muitos dos seus requisitos ao adotar a conduta de atender às demais normas vigentes, e, realizar uma gestão eficiente de suprimentos, mão de obra e procedimentos construtivos.
\end{abstract}

PALAVRAS-CHAVE: Norma de desempenho. Requisitos gerais. Alvenaria estrutural. Planejamento e gestão. 


\section{INTRODUÇÃO}

A introdução dos princípios do desenvolvimento sustentável no âmbito da construção civil e as necessidades de otimização no funcionamento dos edifícios, levaram ao desenvolvimento de métodos que permitam projetar e gerenciar esses empreendimentos com maior detalhamento, conferindo mais atribuições à etapa preliminar. Assim como devem ser previstos os aspectos que garantirão a durabilidade, definida por Cremona (2011) como a capacidade de manter a segurança estrutural, a operacionalidade e as condições de manutenção ao longo do ciclo de vida da estrutura, e a satisfação das necessidades dos usuários no escopo do projeto (LAIR; CHEVALIER; RILLING, 2001; MEACHAM et al., 2003; TALON et al., 2005).

A simultaneidade do conhecimento e a colaboração interdisciplinar são condições fundamentais para o desenvolvimento de melhores produtos. Por esta razão, o uso de softwares que promovem a integração entre os ciclos de desenvolvimento dos produtos faz-se necessário. Garantindo que seja dada ênfase ao projeto conceitual, que fomenta os recursos necessários ao atendimento do ciclo de vida projetado (CAVIERES; GENTRY; AL-HADDAD, 2011; WANG et al., 2002).

A durabilidade está intimamente vinculada ao conceito de sustentabilidade que implica na existência de um equilíbrio entre fatores sociais, ambientais e econômicos. O que pode ser exemplificado com o início das avaliações do desempenho das edificações na Europa, década de 90, por meio de classificações relacionadas ao consumo energético (KERN; SILVA; KAZMIERCZAK, 2014; REIS; LAY, 2010).

No Brasil, foi criada, recentemente, pela Associação Brasileira de Normas Técnicas (ABNT) a norma que parametriza o desempenho das edificações habitacionais, a NBR 15575 (ABNT, 2013) que estabelece requisitos mínimos a serem atendidos pelos sistemas construtivos das edificações, cujos projetos aprovados a partir da sua data de vigência (BRITO et al., 2012). A aplicação dos princípios que visam o desempenho na concepção dos projetos residenciais é essencial em vários sentidos, podendo-se destacam: os vultosos envolvimento e investimento individual e familiar na aquisição de um imóvel, e o longo ciclo de vida do produto. Tais características tornam justificável e necessária a regulamentação das construções habitacionais (RODRIGUES; OLIVEIRA, 2009).

Aliado a isto, tem-se que nos últimos anos houve a criação de muitos programas de apoio e incentivo ao ingresso de estudantes nas Universidades públicas e privadas no Brasil. $\mathrm{O}$ que resultou em um aumento da demanda de vagas nas Instituições de Ensino Superior. Além disso, o número de estudantes matriculados fora do seu estado de origem também aumentou, consideravelmente, devido à adoção do Exame Nacional do Ensino Médio (ENEM) como a principal forma de ingresso nas Universidades. Uma forma alternativa de moradia para os estudantes que migram de cidades, estados e países, são as moradias oferecidas por algumas Universidades Federais. Que são uma tipologia de habitação temporária as quais oferecem acomodações adequadas, espaços reservados aos estudos e convívio social, e, devem propiciar um bom relacionamento entre os moradores e a vizinhança (NAWATE, 2014). 
As Moradias Universitárias são temas de estudos que relacionam essa vivência a um melhor desempenho acadêmico dos alunos inseridos, por se tratarem de um espaço em que são empreendidos esforços com dupla função: residência e ambiente de formação. Tais empreendimentos tornam viável o intercâmbio de culturas e o maior acesso da população de baixa renda à educação superior (GARRIDO; DA SILVA MERCURI, 2013).

Diante deste contexto, o objetivo desta pesquisa é avaliar em um estudo de caso $o$ atendimento dos requisitos gerais e o desempenho estrutural segundo a NBR 15575 (ABNT, 2013) e, possíveis adequações técnico-gerenciais que se fazem necessárias, no processo construtivo em alvenaria estrutural e fundação profunda.

\section{METODOLOGIA}

Para atingir o objetivo executou-se de um estudo de caso em uma obra protocolada na prefeitura da cidade no ano de 2011 (cujo atendimento à norma de desempenho ainda não se aplica) mas que, entretanto, foi executada conforme as exigências das demais normas brasileiras aplicadas à construção civil. Espera-se detectar o que mudaria no processo construtivo (planejamento, projeto, materiais e componentes, execução e uso e manutenção da edificação) com adoção desta norma.

Para a execução deste trabalho foi realizada uma visita técnica no empreendimento. Foram coletados documentos, fotografias do estágio atual e passados da obra. Executou-se ainda avaliação visual e entrevistas com a Responsável Técnica da obra. Analisou-se o cumprimento aos requisitos normativos quanto ao desempenho dos edifícios (Partes 1 -Requisitos Gerais e Parte 2 - Requisitos para os Sistemas estruturais) da NBR 15575 (2013), devido à etapa construtiva (execução do revestimento da fachada) em que a obra se encontrava na data da visita técnica (Figura 1).

Figura 1 - Vista da obra no dia da visita técnica

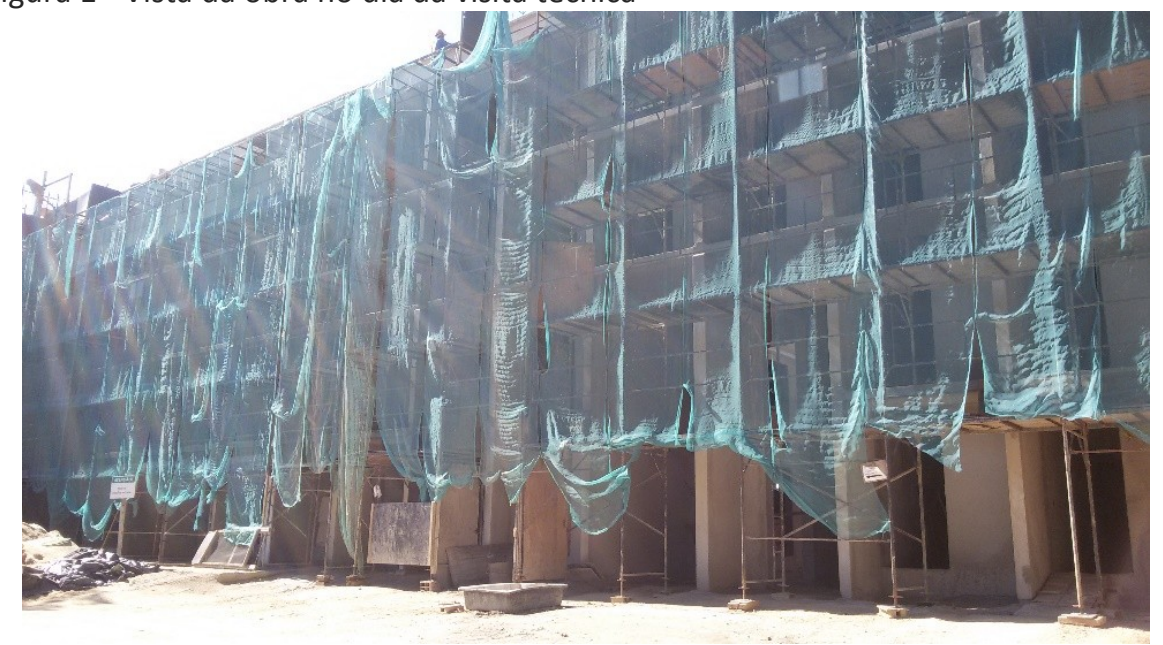

Fonte: autoria própria, (2016)

A Norma de Desempenho, NBR 15575 (ABNT, 2013), contempla todas as edificações habitacionais com qualquer número de pavimentos, todos os sistemas construtivos desde que os projetos tenham sido protocolados nos órgãos competentes após 19/07/2013. Tendo em vista as aplicações da norma, 
conclui-se que o estudo de caso em questão não se enquadraria, por ter sido iniciado dois anos antes de sua vigência e por ser classificado na categoria de edificações multifuncionais. Contudo, destaca-se que é uma edificação habitacional (habitação de estudantes e professores) com permanência relativamente prolongada (de 2 a 5 anos), logo os requisitos desta norma são evidentemente relevantes para conforto e habitabilidade destes usuários.

Assim, a realização deste estudo visa avaliar se o atendimento das normas pré-existentes seria suficiente para garantir o desempenho das edificações e a habitabilidade dos usuários segundo as prescrições da NBR 15.575 (ABNT, 2013). Esta norma é dividida em seis grandes tópicos: 1 - Requisitos Gerais; 2 Requisitos para os sistemas estruturais; 3 - Requisitos para os sistemas de pisos; 4 - Requisitos para os sistemas de vedações verticais internas e externas; 5 Requisitos para os sistemas de coberturas; 6 - Requisitos para os sistemas hidros sanitários. Para este trabalho, serão abordados os tópicos já executados no empreendimento na data da realização do estudo de caso, restringindo o estudo da referida norma às partes 1 e 2 .

\section{ESTUDO DE CASO}

\section{DESCRIÇÃO DA EDIFICAÇÃO}

O presente estudo de caso foi realizado em uma obra cuja finalidade é servir como moradia universitária para estudantes de graduação ou pós-graduação, professores ou técnicos em Minas Gerais. Trata-se de residência temporária, entretanto o estudante contemplado com uma vaga poderá ocupar um dormitório por um tempo médio que varia entre 2 e 5 anos.

Dentre as características do empreendimento, pode-se citar que serão oferecidas 386 vagas. Os prédios são construídos em três terrenos adjacentes a uma das moradias já existentes, de modo a integrar os espaços das duas unidades, com infraestrutura de acesso existente compartilhada. 0 projeto conta com 45 apartamentos distribuídos em 2 torres (torre 1 tem cinco pavimentos, e a Torre 2 quatro andares) e há uma terceira edificação que servirá para abrigar áreas de uso comum. Cada apartamento tem quartos individuais, sala, cozinha, área de serviço e sanitários. No primeiro andar do Bloco 2, há três apartamentos adaptados em conformidade com a NBR 9050 (ABNT, 2004), para abrigar portadores de necessidades especiais, e, a área de convivência entre os Blocos também foi dimensionada contemplando as diretrizes da acessibilidade. As áreas relativas às dependências do empreendimento estão descritas pela Tabela 1. 
Tabela 1- quantitativo das áreas das dependências do empreendimento.

\begin{tabular}{cc} 
DEPENDENCIAS & ÁREA $\left(\mathrm{m}^{2}\right)$ \\
\hline Bloco 1 - Área construída - 5 pavimentos & $4.485,01$ \\
Bloco 2 - Área construída - 4 pavimentos & $3.559,12$ \\
Bloco 3 - Área construída & 277,23 \\
Estacionamento & $1.378,77$ \\
Acesso e rampas & $1.438,87$ \\
Reservatório inferior & 71,84 \\
Área de Resíduos Sólidos, Casa de bombas e Casa de gás & 96,79 \\
Jardins e gramado & $2.513,51$ \\
Área total - Externa & $5.380,96$ \\
\hline
\end{tabular}

Fonte: Sacco; Schuab; Santos, (2016) - adaptado.

A implantação dos prédios no terreno está representada pela Figura 2 (a), que ilustra a disposição entre torres de apartamentos (Bloco 1 e Bloco 2) além da edificação da área de uso comum (Bloco 3 ). Ilustra também o espaço reservado aos estacionamentos, jardins e rampas. Para fins didáticos, foram destacados com a numeração " 1 " e " 2 " na representação do Bloco 2, os apartamentos cujo layout estão ampliados na Figura 3 (a) e (b). O número "1" representa os apartamentos que contém um quarto e um banheiro adaptados para atender aos alunos portadores de necessidades especiais. O número " 2 " representa as unidades de apartamento tipo. A Figura 3 (b) apresenta a disposição construtiva do Bloco 3, que será utilizado como área de convivência para os estudantes, oferecendo atividades recreativas extracurriculares.

Figura 1- Implantação e Área de uso comum - Bloco 3.



(a) 


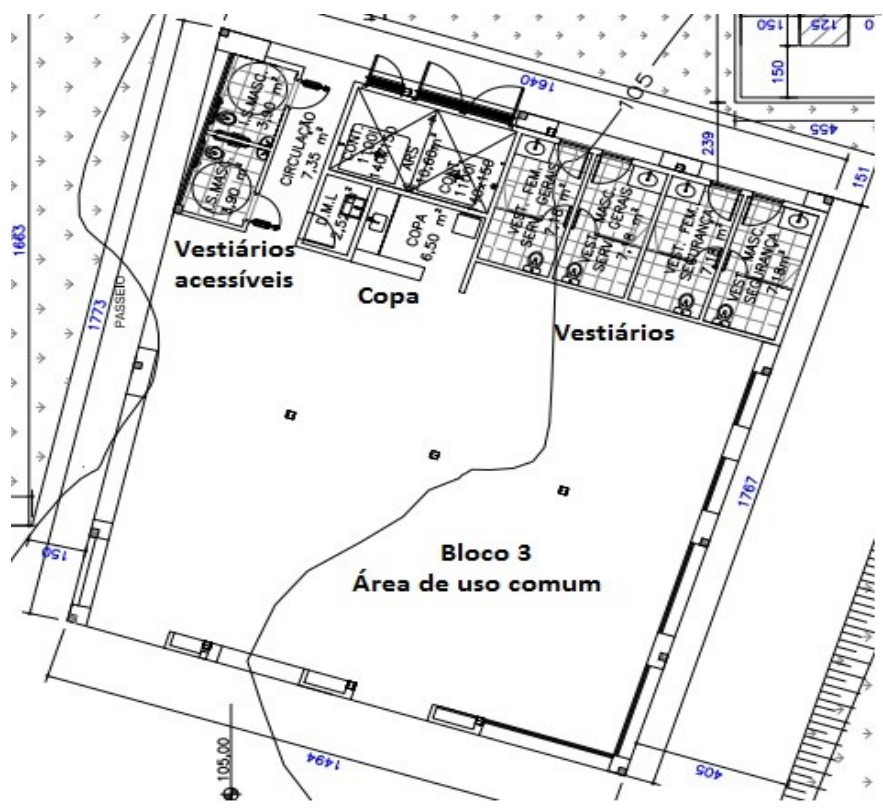

(b)

Fornecida pela construtora, (2016) - adaptado.

\section{REQUISITOS GERAIS}

\section{Projeto e Controles}

Os projetos foram executados por empresas especializadas contratadas individualmente por cada modalidade necessária. Não foi utilizada a plataforma BIM (Building Information Modeling) que, segundo Barros; Rêgo (2010); Cespo; Ruschel (2007); Witicovski; Emilia; Garcia (2009), viabiliza a quantificação automática dos elementos construtivos de forma precisa e com eficiência. $E$, consequentemente, reduz a variabilidade na orçamentação, além de gerenciamento da informação da construção no ciclo de vida do projeto. 
Figura 3 - Layout dos apartamentos tipo e acessíveis do 1o pavimento do Bloco 2.

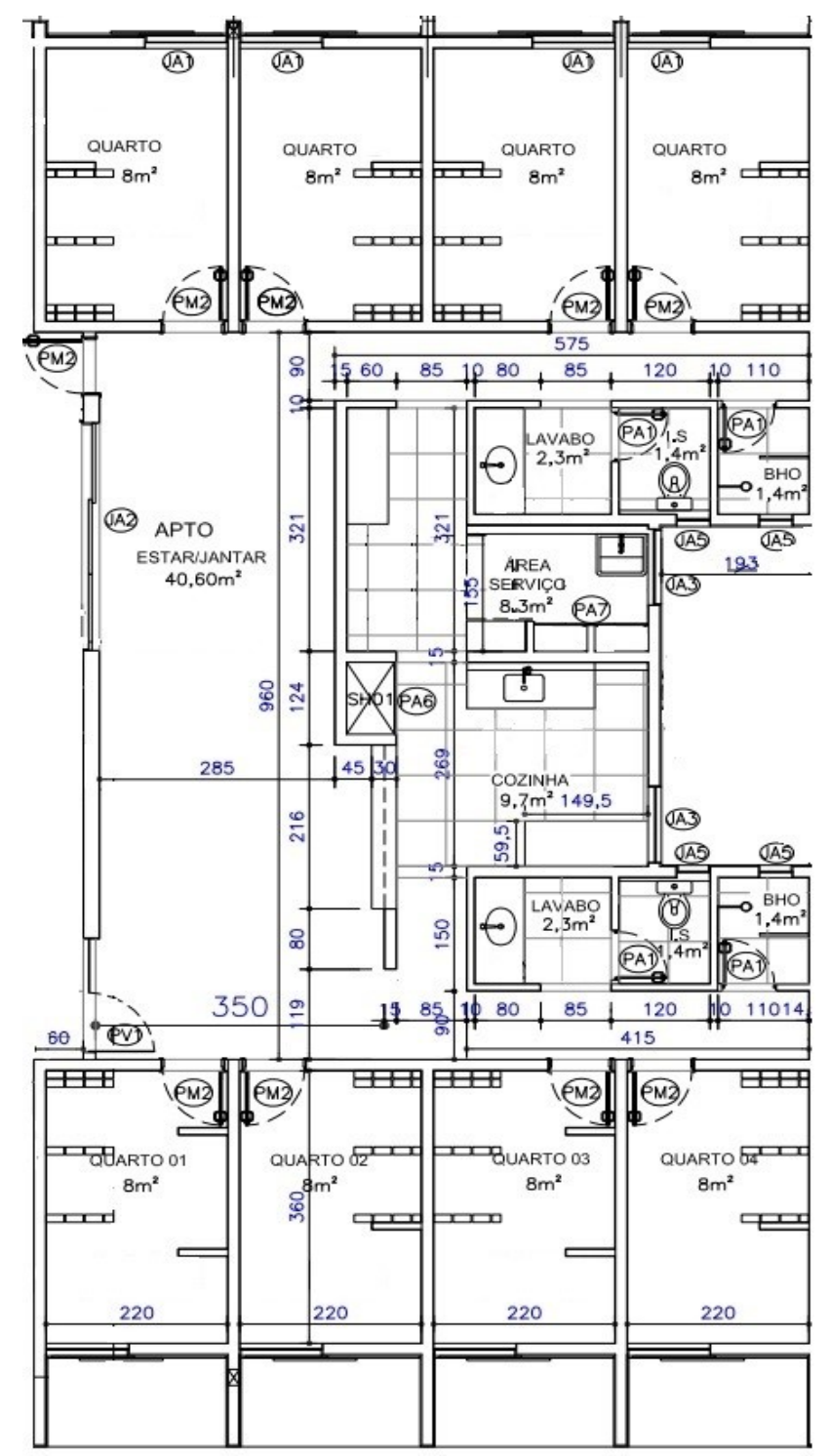

(a) 


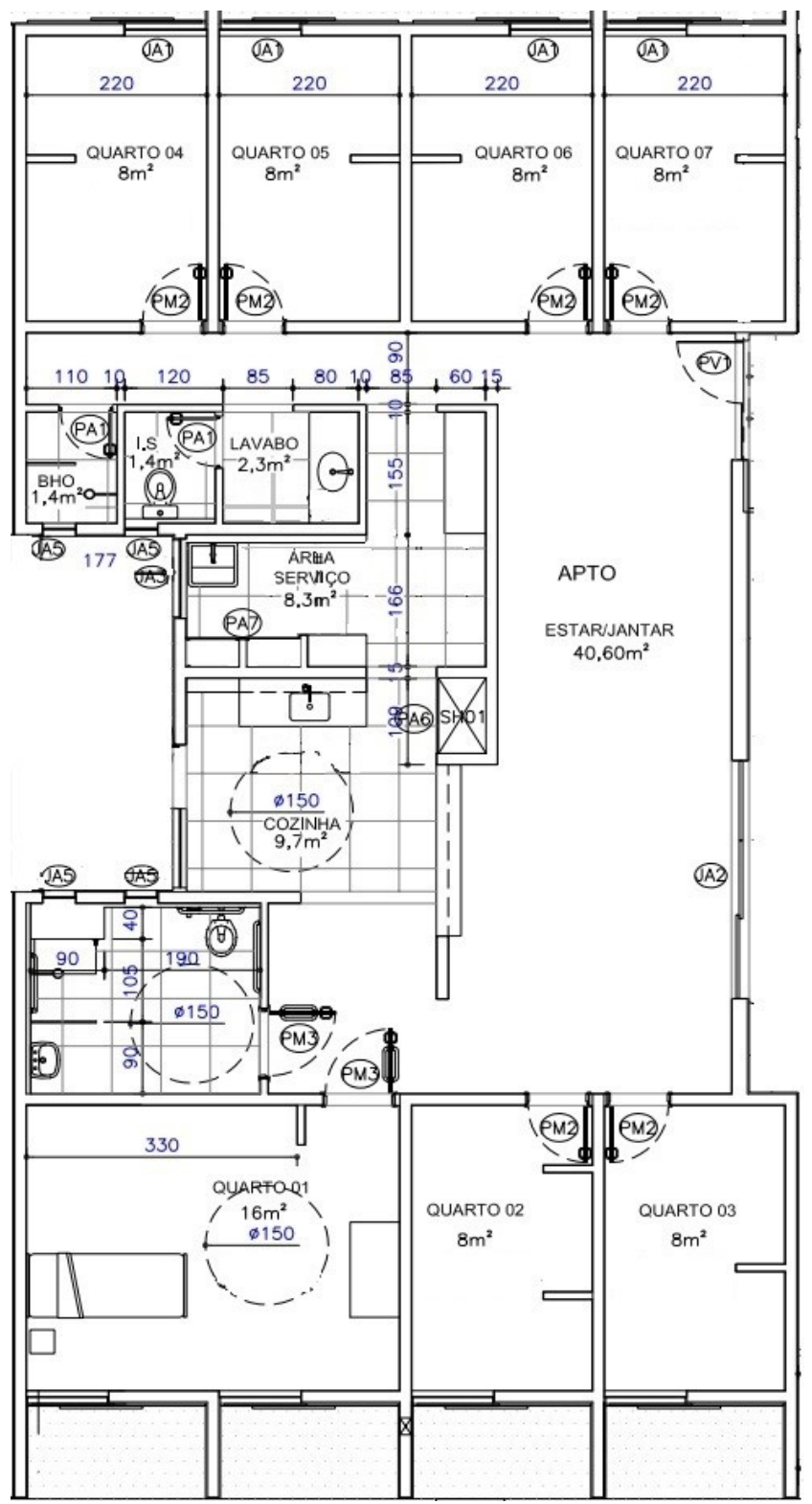

(b)

Fornecida pela construtora, (2016) - adaptado

Entretanto, há um profissional especializado, com formação acadêmica em arquitetura, responsável pela compatibilização dos projetos trabalhando diariamente no escritório do canteiro de obras. Foi relatado, na entrevista realizada com a engenheira, que o nível de detalhamento dos projetos, para alguns casos específicos, não é suficiente. Fator que tornou necessária a contratação exclusiva desse profissional.

Não são adotados programas de garantia de qualidade, como o PBQP-H (Programa Brasileiro de Qualidade e Produtividade no Habitat), que racionaria a produção e melhoria efetivamente no controle de processos, com a diminuição do retrabalho, do desperdício de materiais e do tempo de mão de obra ociosa nos canteiros (MELGAÇO et al., 2004 e ARAÚJO et al., 2002). Justifica-se este posicionamento, devido a fundação responsável pela construção não ser 
especializada no setor construtivo e sim na administração de moradias, sendo contratado profissionais e consultores para suprir esta carência.

Após a realização de alterações nos projetos, quando necessárias, a versão atualizada é enviada para a obra, onde são disponibilizadas 3 cópias da versão mais recente de cada prancha para utilização no canteiro. Os demais controles diários executados no escritório do canteiro são: a execução do diário de obras, feito pela técnica em edificações ou pela engenheira; controle de frequência por meio de ponto eletrônico e, atualmente, há ocorrência da implantação de fichas de verificação de serviços.

Em relação à acessibilidade do canteiro de obras para portadores de necessidades especiais, o projeto contempla as diretrizes de construção acessível nas áreas comuns. Durante a execução da obra foram contratados funcionários portadores de necessidades especiais, mas nenhum deficiente visual ou cadeirante.

\section{Materiais}

A compra dos materiais era feita através de licitação, entretanto, são exigidas especificações às quais os materiais devem atender, e entre os que cumprem os requisitos mínimos se escolhe o de menor valor. Quando há ocorrência de produtos cujas marcas não são consolidadas pelo mercado, são realizados testes específicos para aferir as características desse material anteriormente à compra. O controle do estoque é realizado pelo almoxarife, através de fichas elaboradas, pelo setor de planejamento, especificamente para esse fim. A realização da solicitação de compra dos materiais é autorizada pela engenharia e encaminhada ao setor de compras, onde são executadas as licitações.

O armazenamento da maioria dos materiais de construção é feito em almoxarifado, cujo gerenciamento é realizado por funcionários qualificados, em tempo integral. Há particularidades na armazenagem de alguns itens, devido aos grandes volumes que ocupam e à demanda por facilidade de transporte na rotina da construção. Dentre eles, destacam-se a areia e a brita, que são alocadas em baias separadas fisicamente, mas não cobertas. As barras de aço que são armazenadas em conformidade às recomendações, sendo a disposição desse material próxima à estação de trabalho destinada ao corte e dobra das armaduras.

Os blocos de concreto são recebidos com suas respectivas identificações e armazenados em pallets, dispostos próximos aos prédios em construção. É realizada a inspeção visual, no momento do recebimento, que consiste na contagem dos blocos e na observação de danos aparentes. Previamente ao envio dos lotes de blocos à obra, é realizada a seleção aleatória das amostras na fábrica. Essas são enviadas ao laboratório de controle tecnológico, para que sejam ensaiadas conforme as recomendações da norma NBR 15961-2 (ABNT, 2011). Quando aprovados, os lotes são enviados para a obra para serem utilizados. O concreto utilizado nas estacas, pilares, vigas e lajes foi o usinado. Ressalta-se, também, que a autora principal deste estudo foi a encarregada da execução dos ensaios de controle tecnológico dos elementos estruturais da 
edificação e acompanhou parte dos serviços realizados durante a etapa de construção da estrutura.

A argamassa industrializada e o cimento utilizado na fabricação do graute são armazenados em locais apropriados, cobertos e protegidos de intempéries, apoiados sobre pallets em piso argamassado, conforme as recomendações da NBR 11578 (ABNT, 1997). A utilização desses materiais é feita considerando as datas de recebimento e de vencimento informadas nas embalagens dos produtos. Os quais são dispostos pelo método Primeiro que entra Primeiro que sai (PEPS), que, segundo (OLIVEIRA, 2011; POZO, 2010), é um método baseado na cronologia. E, assim, os materiais com o prazo de validade mais próximo do vencimento ficam em pilhas mais acessíveis para uso, prevenindo a perda e o desperdício de materiais. Para a mobilização dos pallets, há na obra uma mini carregadeira operada por funcionário qualificado.

\section{Funcionários}

A empresa conta com um grande número de profissionais fixos, por se tratar de uma iniciativa pública há várias restrições quanto à contratação de empreiteiras. Somente são terceirizadas as atividades de execução das estacas (já realizadas na etapa de fundações profundas), a instalação de esquadrias e a aplicação de gesso, as quais ocorrerão em etapas posteriores à realização deste artigo.

A contratação dos funcionários é realizada através da análise de currículo e da aplicação de uma prova de conhecimentos básicos. Como o pagamento dos salários é realizado por meio de depósito bancário, é proibida a contratação de funcionários analfabetos e cabe à administração garantir essa o cumprimento dessa exigência. 0 maior número de funcionários contratados ocorreu na etapa da execução da alvenaria estrutural, no período entre janeiro e maio de 2015, cuja quantidade aproximada foi de 149 trabalhadores.

O canteiro de obras foi projetado para contemplar essa demanda, prevista na fase de aprovação inicial. Há um técnico de segurança do trabalho, em tempo integral, e é prestada a consultoria de uma empresa especializada que, periodicamente, fornece cursos, palestras, realiza inspeções e distribui material educativo para os funcionários através de visitas de um engenheiro de segurança. A empresa realiza o Diálogo Diário de Segurança (DDS) que, segundo Silva; Mendonça (2012) assegura, diariamente, o controle do que foi proposto nos treinamentos.

Há uma enfermaria física no canteiro de obras, que conta com uma enfermeira em horário integral. Para que sejam realizados os primeiros socorros, em casos de acidentes, e avaliados os funcionários com queixas de indisposição ou mal-estar súbito. A obra conta, também, com PCMAT (Programa de Condições e Meio Ambiente de Trabalho na Indústria da Construção) que estabelece um programa permanente de controle dos riscos ambientais existentes, atuando no campo da prevenção, da preservação e da proteção dos trabalhadores (SILVA et al., 2014). Concomitantemente à execução do PCMAT, é feita uma interconexão com o Programa de Controle Médico e Saúde Ocupacional (PCMSO), que determina os aspectos obrigatórios que as empresas devem elaborar ou implementar, objetivando promover e preservar a saúde de todos os 
trabalhadores (CERATTO et al., 2014; LUCCHINE; GOMES, 2015; RONCON; OLIVEIRA; BELTRAME, 2015).

\section{Verificação de Conformidade à NBR 15575-1}

Uma vez levantados os dados para análise da conformidade com a Norma de Desempenho, foram realizadas análises, e, definida a situação do empreendimento analisado como: conforme, não conforme, não analisado quando não se obteve acesso aos dados necessários para a análise - ou não prevista, quando o item não será contemplado pelos executores. As análises realizadas estão resumidas nas Tabela 2-13.

Tabela 1 - requisitos do usuário.

\begin{tabular}{ccc} 
Requisitos do Usuário & Conformidade & \\
\hline Segurança & Estrutural & Conforme \\
& Contra o fogo & Não analisado \\
& Uso e operação & Conforme \\
& Estanqueidade & Conforme \\
& Desempenho térmico & Conforme \\
& Desempenho acústico & Conforme \\
Desempenho lumínico & Conforme \\
Habitabilidade & Saúde, higiene e & Não analisado \\
& qualidade do ar & \\
& Funcionalidade e & Conforme \\
& acessibilidade & \\
& Conforto tátil e & Não analisado \\
& antropodinâmico & Não prevista \\
& Durabilidade & Não prevista \\
& Manutenabilidade & Conforme \\
\hline
\end{tabular}

Pesquisa de campo (2016).

Quanto aos requisitos do usuário, à avaliação do desempenho, às incumbências dos intervenientes e à segurança no uso e operação foram confeccionadas as: Tabela 1, Tabela 2, Tabela 3, Tabela 4 e Tabela 5, respectivamente. A análise dos critérios e do cumprimento dos mesmos foi realizada individualmente para cada parâmetro, por meio da análise dos projetos e documentação regulamentária disponibilizados pela construtora, por meio da entrevista à gestora da obra quanto aos aspectos não documentados e, também, por meio da experiência de estágio supervisionado de um dos autores - no período de 15 meses, no empreendimento estudado. 
Tabela 3- Avaliação do desempenho.

\begin{tabular}{|c|c|c|}
\hline \multicolumn{3}{|c|}{ Avaliação do desempenho Conformidade } \\
\hline \multicolumn{3}{|c|}{ Diretrizes } \\
\hline Diretrizes para & $\begin{array}{l}\text { Avaliação das características (topográficas, } \\
\text { geológicas, hidrológicas, presença de gases, entre } \\
\text { outros) do local }\end{array}$ & Conforme \\
\hline $\begin{array}{l}\text { implantação e } \\
\text { entorno }\end{array}$ & $\begin{array}{l}\text { Previsão de interações com construções no entorno } \\
\text { atendendo à NBR 12722, (1992) e NBR } 8044 \text {, (1983) }\end{array}$ & Conforme \\
\hline & $\begin{array}{l}\text { Consideração das condições de agressividade do } \\
\text { solo, do ar e da água }\end{array}$ & Conforme \\
\hline & $\begin{array}{l}\text { Adoção de sistema construtivo já utilizado em outras } \\
\text { obras e realização de inspeções em campo }\end{array}$ & Conforme \\
\hline Metodos de & $\begin{array}{l}\text { Ensaios de laboratório realizados com amostragem } \\
\text { aleatória }\end{array}$ & Conforme \\
\hline $\begin{array}{l}\text { desempenho, } \\
\text { amostragem, }\end{array}$ & $\begin{array}{l}\text { Relatórios de ensaios laboratoriais conforme às } \\
\text { normas prescritivas }\end{array}$ & Conforme \\
\hline de avaliação & $\begin{array}{l}\text { Caracterização das amostras com todas as } \\
\text { informações que a identifiquem }\end{array}$ & Conforme \\
\hline do sistema & $\begin{array}{l}\text { Relatórios de avaliação do desempenho analisados } \\
\text { por competentes técnicos }\end{array}$ & Conforme \\
\hline $\begin{array}{l}\text { Relação entre } \\
\text { normas }\end{array}$ & $\begin{array}{l}\text { Análise dos requisitos suplementares às Normas para } \\
\text { atendimento integralizado (como o código de } \\
\text { edificações de Belo Horizonte) }\end{array}$ & Conforme \\
\hline
\end{tabular}

Pesquisa de campo (2016).

Tabela 4- Incubências dos intervenientes.

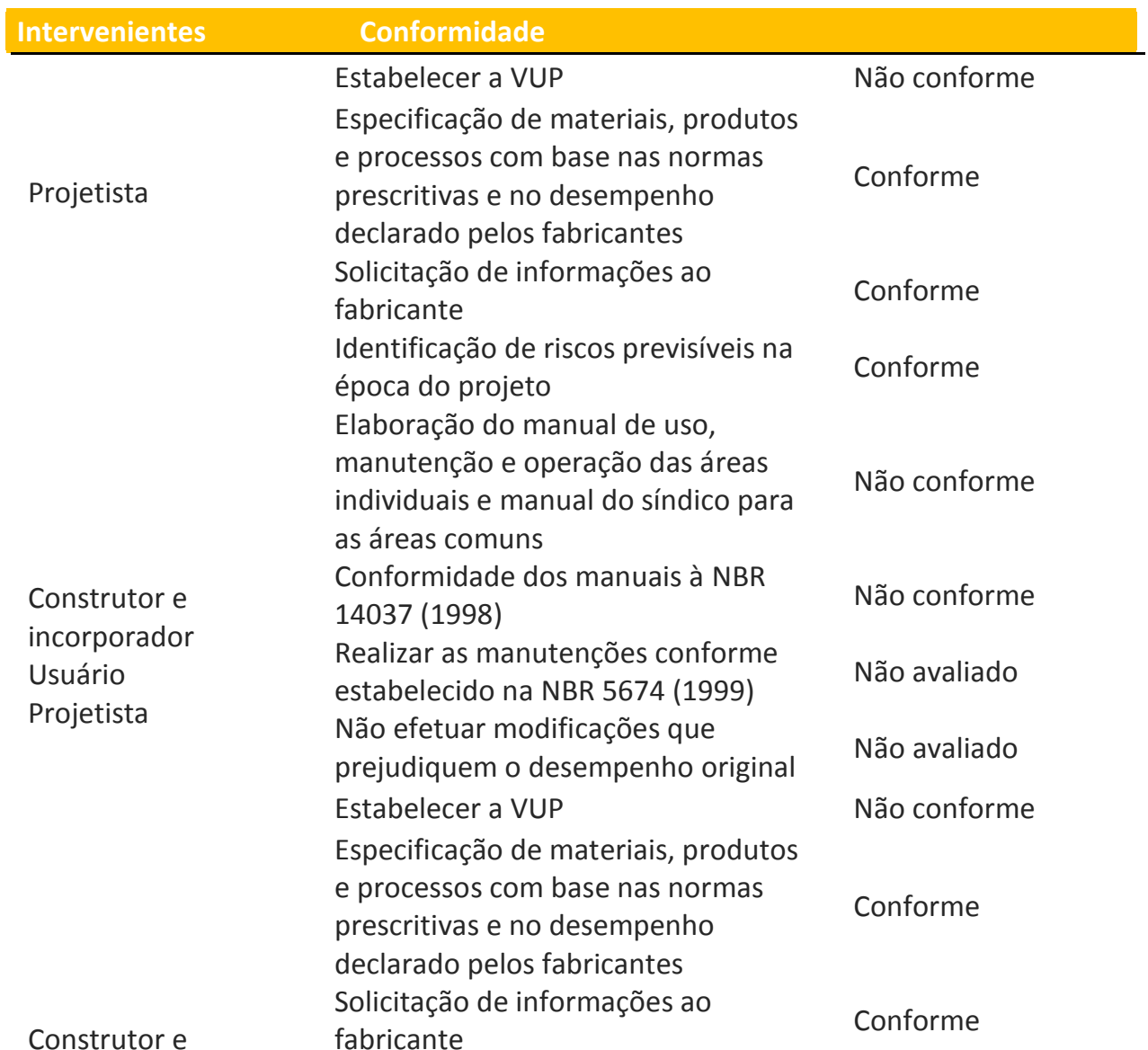


incorporador

Identificação de riscos previsíveis na

época do projeto

Conforme

Elaboração do manual de uso,

manutenção e operação das áreas

individuais e manual do síndico para

Não conforme

as áreas comuns

Pesquisa de campo (2016).

Tabela 5 - Segurança no uso e na operação.

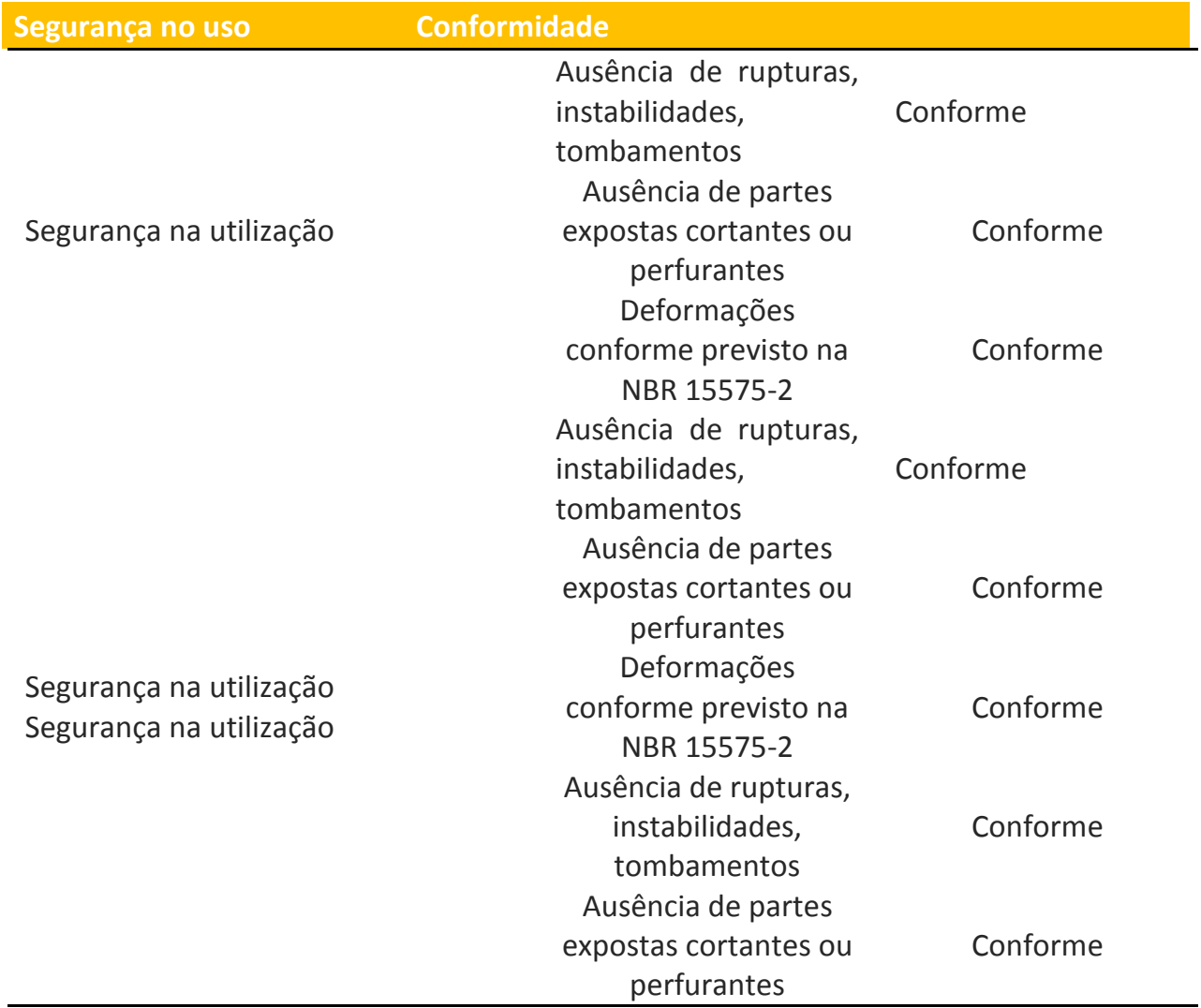

Pesquisa de campo (2016).

- Desempenho térmico, estanqueidade e resistência ao fogo.

De acordo com Silva (2014), com a utilização de blocos estruturais de concreto com espessura de $15 \mathrm{~cm}$ e resistência de 4 a $6 \mathrm{MPa}$, como no presente estudo de caso, são garantidas as condições de desempenho térmico, estanqueidade - Tabela 6, e resistência ao fogo.

Os parâmetros do desempenho térmico admitido para cada cidade são baseados na sua localização nas Zonas Bioclimáticas NBR 15575 (ABNT, 2013). Nestas condições Belo Horizonte, cidade de estudo, situa-se na Zona 3, e precisa de materiais nas suas paredes com transmitância térmica (U) menor que 3,7 $\mathrm{W} / \mathrm{m}^{2} . \mathrm{k}$ para cores claras e menos que $2,5 \mathrm{~W} / \mathrm{m}^{2} . \mathrm{k}$ para cores escuras e, capacitância térmica (CT) maior que $130 \mathrm{~kJ} / \mathrm{m}^{2} . \mathrm{k}$. No caso do bloco de $15 \mathrm{~cm}$ e com revestimento argamassado por fora e gesso interno estes valores são de $U$ igual a $2,86 \mathrm{~W} / \mathrm{m}^{2} . \mathrm{k}$ e CT igual a $222 \mathrm{~kJ} / \mathrm{m}^{2} . \mathrm{k}$ (INMETRO, 2013), logo este sistema de vedação atende aos requisitos térmicos, sem a necessidade de simulação computacional. 
Tabela 6- Estanqueidade.

\begin{tabular}{|c|c|c|}
\hline Estanqueidade & dade & \\
\hline & $\begin{array}{l}\text { Drenagem de águas de } \\
\text { chuva e lotes vizinhos }\end{array}$ & Conforme \\
\hline Estanqueidade a fontes de umidade & $\begin{array}{l}\text { Conformidade à NBR } \\
9575 \text { (ABNT, 2010) }\end{array}$ & Conforme \\
\hline & $\begin{array}{l}\text { Impermeabilização de } \\
\text { fundações e pisos em } \\
\text { contato com o solo }\end{array}$ & Conforme \\
\hline $\begin{array}{l}\text { Estanqueidade à água de chuva e à } \\
\text { umidade do solo e do lençol freático }\end{array}$ & $\begin{array}{l}\text { Estanqueidade às } \\
\text { fontes de umidades } \\
\text { internas - partes que } \\
\text { tenham a } \\
\text { possibilidade de ficar } \\
\text { em contato com a } \\
\text { água gerada na } \\
\text { ocupação }\end{array}$ & Conforme \\
\hline
\end{tabular}

Pesquisa de campo (2016).

- Durabilidade.

A durabilidade de um sistema e seus componentes está diretamente relacionada com a vida útil prevista de todas as partes que os compõe. A Tabela 7 apresenta a vida útil mínima de cada sistema da edificação, os quais deverão ser levados em consideração no ato do projeto.

Tabela 7- Vida útil de projeto (VUP).

\begin{tabular}{cc} 
Sistema mínima em anos & \\
\hline Estrutura & $\geq 50$, conforme NBR 8681 \\
Pisos internos & $\geq 13$ \\
Vedação vertical externa & $\geq 40$ \\
Vedação vertical interna & $\geq 20$ \\
Cobertura & $\geq 20$ \\
Hidrossanitário & $\geq 20$ \\
\hline
\end{tabular}

Considerando a periodicidade e processos de manutenção conforme a NBR 5674 (ABNT, 1999)e especificados no respectivo manual de uso, operação e manutenção entregue ao usuário elaborado em atendimento à NBR 14037(ABNT, 1998).

Pesquisa de campo (2016).

Na ausência de indicação em projeto da VUP dos sistemas, serão adotados os valores relacionados na Tabela 7 para o desempenho mínimo.

- Funcionalidade e acessibilidade

As dimensões mínimas de altura do pé direito para edificações prescritos pela NBR 15575, (2013) e pelo Código de Edificações de Belo Horizonte, (2009) são:

- Altura mínima do pé direito $\geq 2,50 \mathrm{~m}$ (Belo Horizonte $=2,60$ )

- Em vestíbulos, halls, corredores, instalações sanitárias e despensas é permitido pé direito mínimo de 2,30 (Belo Horizonte $=2,40$ ) $\mathrm{m}$. 
Tabela 8- Áreas mínimas dos ambientes da habitação compatíveis com as necessidades humanas.

\begin{tabular}{|c|c|c|c|c|c|}
\hline Atividade & Mobiliário & \multicolumn{2}{|c|}{ Área mínima } & \multicolumn{2}{|r|}{ Área apta } \\
\hline \multirow{5}{*}{$\begin{array}{l}\text { Dormitório } \\
\text { uma pessoa }\end{array}$} & Cama de solteiro & 0,80 & 1,90 & \multirow{5}{*}{$8,0 \mathrm{~m}^{2}$} & \multirow{5}{*}{$8 \mathrm{~m}^{2}$} \\
\hline & Guarda-roupa & 1,20 & 0,50 & & \\
\hline & Criado-mudo & 0,50 & 0,50 & & \\
\hline & $\begin{array}{l}\text { Mesa de estudo } \\
\text { (opcional) }\end{array}$ & 0,8 & 0,60 & & \\
\hline & $\begin{array}{l}\text { Circulação } \\
\text { mínima }\end{array}$ & 0,50 & 0,50 & & \\
\hline \multirow{4}{*}{$\begin{array}{l}\text { Sala de estar } \\
\qquad \quad \text { Largura } \\
\text { mínima de } \\
2,40 \mathrm{~m}\end{array}$} & $\begin{array}{ll}\text { Sofá de três } \\
\text { lugares }\end{array}$ & 1,50 & 0,70 & \multirow{4}{*}{$12,0 \mathrm{~m}^{2}$} & \multirow{4}{*}{$40 \mathrm{~m}^{2}$} \\
\hline & Armário & 0,80 & 0,50 & & \\
\hline & Poltrona & 0,50 & 0,70 & & \\
\hline & Circulação & 0,50 & 0,50 & & \\
\hline \multirow{7}{*}{ Cozinha } & Fogão & 0,55 & 0,60 & \multirow{7}{*}{$4,0 \mathrm{~m}^{2}$} & \multirow{7}{*}{$9,7 \mathrm{~m}^{2}$} \\
\hline & Geladeira & 0,70 & 0,70 & & \\
\hline & Pia & 1,20 & 0,50 & & \\
\hline & $\begin{array}{l}\text { Armário sobre a } \\
\text { pia }\end{array}$ & - & - & & \\
\hline & $\begin{array}{l}\text { Apoio } \quad \text { para } \\
\text { refeição }\end{array}$ & - & - & & \\
\hline & Circulação & 0,85 & 0,85 & & \\
\hline & Circulação & 0,75 & 0,75 & & \\
\hline \multirow{4}{*}{$\begin{array}{l}\text { Sanitários } \\
\bullet \quad \text { Largura } \\
\text { mínima } \\
1,10 \mathrm{~m}\end{array}$} & Lavatório & 0,39 & 0,29 & \multirow{4}{*}{$2,40 \mathrm{~m}^{2}$} & \multirow{4}{*}{$5,10 \mathrm{~m}^{2}$} \\
\hline & Chuveiro & 0,7 & 0,9 & & \\
\hline & Vaso sanitário & 0,6 & 0,7 & & \\
\hline & Circulação & 0,4 & 0,4 & & \\
\hline \multirow{3}{*}{$\begin{array}{c}\text { Área de serviços } \\
-\quad \text { Largura } \\
\text { mínima } \\
0,90 \mathrm{~m}\end{array}$} & Tanque & 0,52 & 0,53 & \multirow{3}{*}{$\begin{array}{c}\text { Não } \\
\text { especificado }\end{array}$} & \multirow{3}{*}{$8,30 \mathrm{~m}^{2}$} \\
\hline & $\begin{array}{l}\text { Máquina de lavar } \\
\text { roupas }\end{array}$ & 0,6 & 0,65 & & \\
\hline & Circulação & 0,5 & 0,5 & & \\
\hline
\end{tabular}

*Retirada da Lei 9275, (2009), Código de edificações de Belo Horizonte, (2009); Pesquisa de campo (2016).

A Tabela 8 apresenta as áreas mínimas, por cômodo, prescritas pelo Código de Edificações de Belo Horizonte, sendo a última coluna representativa das áreas, por cômodo, dos apartamentos-tipo da edificação analisada. 
Tabela 9- Iluminação natural.

\begin{tabular}{|c|c|}
\hline Dependência & Iluminação geral (lux) \\
\hline $\begin{array}{l}\text { Sala de estar, dormitório, copa/cozinha, área de } \\
\text { serviço }\end{array}$ & $\geq 60$ \\
\hline $\begin{array}{l}\text { Banheiro, corredor ou escada interna, corredor de } \\
\text { uso comum, escadaria de uso comum, garagens, } \\
\text { demais ambiente }\end{array}$ & Não requerido \\
\hline \multicolumn{2}{|l|}{ Pesquisa de campo (2016). } \\
\hline $\begin{array}{l}\text { Deve-se verificar e atender às condições mín } \\
\text { cal, por esse motivo foi consultado o Código de } \\
\text { ra conferência dos dados. Uma vez que o projet } \\
\text { requisitos de iluminação natural e ventilação, }\end{array}$ & $\begin{array}{l}\text { ueridas pela legislação } \\
\text { fões de Belo Horizonte } \\
\text { etônico está conforme }\end{array}$ \\
\hline
\end{tabular}

Para os edifícios multipiso, são permitidos, para as dependências situadas no pavimento térreo ou em pavimentos abaixo da cota da rua, níveis de iluminância ligeiramente inferiores aos valores especificados na tabela acima (diferença máxima de $20 \%$ em qualquer dependência).

- Adequação ambiental

A Tabela 10 apresenta os requisitos avaliados para a adequação ambiental da edificação. A conformidade foi avaliada por meio de entrevista com a gestora da obra analisada.

Tabela 10- Adequação ambiental.

\section{Adequação ambiental}

Projetos e construção e mantidos de forma a minimizar as alterações no ambiente

Consideração dos riscos de desconfinamento de solo, deslizamentos de taludes, enchentes, erosões, assoreamento de vales ou cursos d'água, lançamento de esgoto a céu aberto, contaminação do solo ou da água por efluentes ou outras substâncias, além de outros riscos similares

Atendimento à NBR 8044 (ABNT, 1983), bem como à legislação vigente

Implementação de um plano de gestão de resíduos no canteiro

Exploração e consumo racionalizado de recursos minerais, objetivando a menor degradação ambiental, menor consumo de água, de energia e matérias-primas

Utilização de materiais que causem menor impacto ambiental

Utilização de madeira cuja origem possa ser comprovada mediantes apresentação de certificação legal ou provenientes de plano de manejo aprovado pelos órgãos ambientais

Consideração de projetos para regularização do consumo de água e deposição de esgotos no uso e ocupação da habitação

Consideração de projeto que minimize o consumo de energia no uso e ocupação
Conformidade

Conforme

Conforme

Conforme

Conforme

Conforme

Não conforme

Conforme

Conforme

Conforme 
Pesquisa de campo (2016).

\section{- Manutenabilidade}

No presente trabalho não foram abordados os requisitos quanto à manutenabilidade, pois não há previsão de planejamento desse item. Já para os tópicos de conforto tátil e antropodinâmico e saúde, higiene e qualidade do ar, não foram coletados dados suficientes para realização da análise.

\section{REQUISITOS ESTRUTURAIS}

\section{Fundações Profundas - Estacas}

O processo construtivo adotado, para a execução das fundações profundas, foi o de estaca hélice contínua monitorada, ilustrado pela

Figura 4 (a). O período de execução dos serviços ocorreu entre os meses de abril e maio de 2014. Para aferição dos serviços executados e garantia do desempenho foram realizados os seguintes ensaios: prova de carga estática, prova de carga dinâmica e teste de integridade das estacas.

Figura 2- (a) Execução das estacas; (b) Prova de Carga Estática e (c) Prova de Carga Dinâmica.

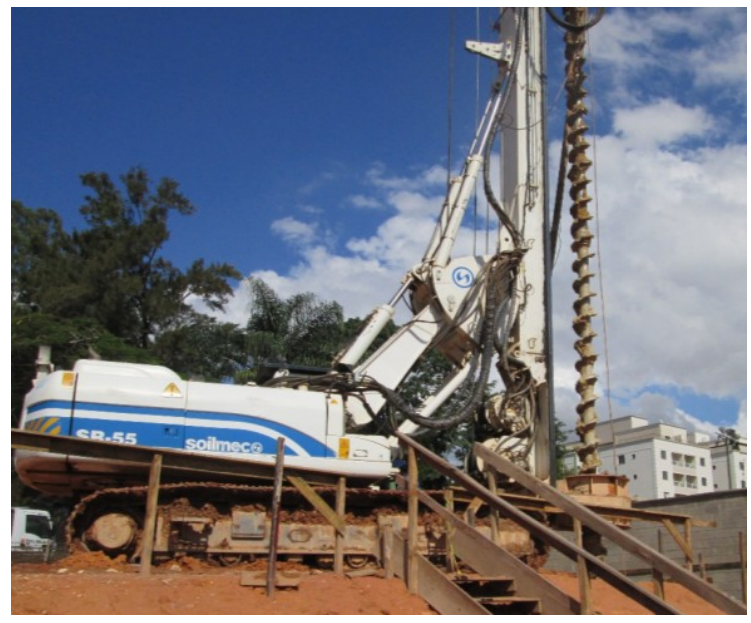

(a)

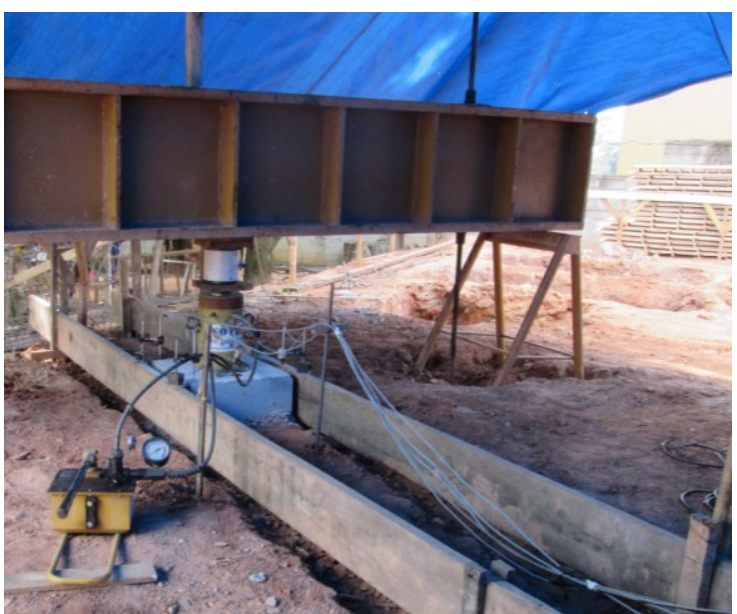

(b) 
(c)

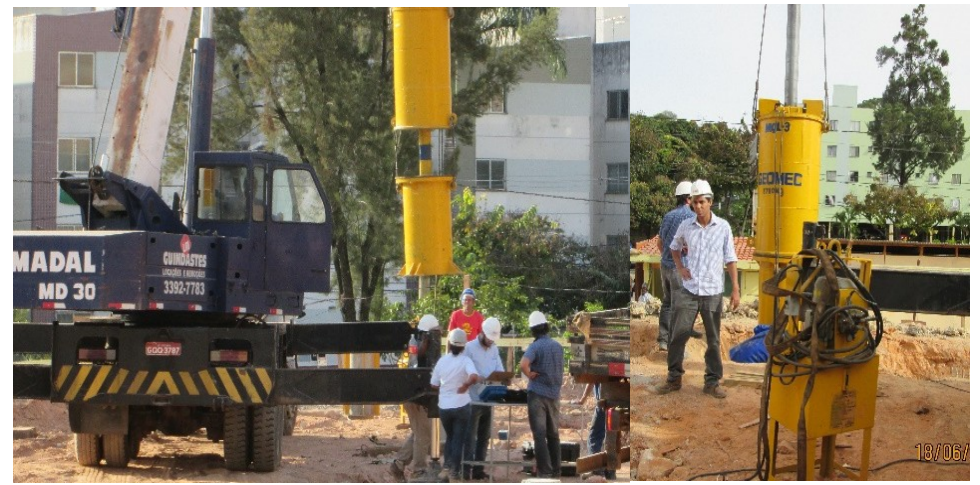

Fonte: Fornecida pela construtora, (2016).

- Prova de carga estática (PCE): (Figura 4 - b) tem como objetivo a determinação da capacidade de carga real da estaca, de recalques, da resistência de ponta, da resistência do atrito lateral, e, do coeficiente de segurança. Fornece a avaliação do comportamento da carga em detrimento ao deslocamento (CINTRA et al., 2013). A NBR 12131 (ABNT, 1992), detalha que, na execução do ensaio, aplicam-se esforços estáticos, com cargas controladas e que serão crescentes à estaca. $\mathrm{E}$, no mesmo instante, medem-se os deslocamentos do topo e da base. A NBR 6122 (ABNT, 2010), ressalta que, nas condições do estudo em questão, o ensaio é facultativo. Realizou-se PCE em cinco estacas, sendo uma no Bloco 2 e as demais no Bloco 1.

- Prova de carga dinâmica (PDA): este ensaio se difere da prova de carga estática por aplicar esforços dinâmicos, através de golpes do martelo num sistema de percussão adequado, no qual são medidas as ondas de vibração geradas pelos golpes. Tem por objetivo determinar a capacidade de ruptura da interação estaca-solo, realizando leituras em diversas estacas em pouco tempo (PIUCCO, 2014). A amostragem consistiu de 10 PDA.

- Teste de integridade de estacas (PIT): (Figura 4 - c) desenvolvido para detectar defeitos perigosos, tais como: fissuras significativas, falhas na concretagem, variações do comprimento da estaca e reduções de diâmetros. Entretanto, este ensaio não informa sobre a capacidade de carga da estaca, a qual deve ser discriminada em ensaios de carregamento estático ou dinâmico. $O$ PIT garante a determinação das características de todas as estacas, além de se tratar de um ensaio não destrutivo (CHIODINI et al., 2013; PIUCCO, 2014). Foi prevista a realização do PIT em todas as estacas da edificação. Contudo optou-se por suprimir 4 ensaios no Bloco 2 devido à dificuldade executiva e, coincidentemente, baixa previsão da carga de trabalho, sendo ensaiadas 378 estacas.

De acordo com o relatório de consultoria, após às análises preliminares dos ensaios as estacas de fundações dos Blocos 1 e 2 estão aptas a receberem as cargas da superestrutura prevista no projeto estrutural de referência (SOLU, 2014). Foi realizado, também, o controle tecnológico total do concreto auto adensável utilizado na concretagem das estacas através da moldagem de corpos de prova e ensaio dos mesmos, em conformidade com as normas NBR 5738 (ABNT, 2003) e NBR 5739 (ABNT, 2007). 
Executou-se a conexão entre a distribuição das cargas do edifício para as estacas através de vigas baldrame (Figura 5 ) apoiadas diretamente sobre blocos na transição entre a estaca e a viga. A execução ocorreu no período de entre junho e agosto de 2014 para o Bloco de apartamentos 2 e entre setembro e outubro de 2014 para o Bloco 1.

Figura 3- Execução do baldrame.

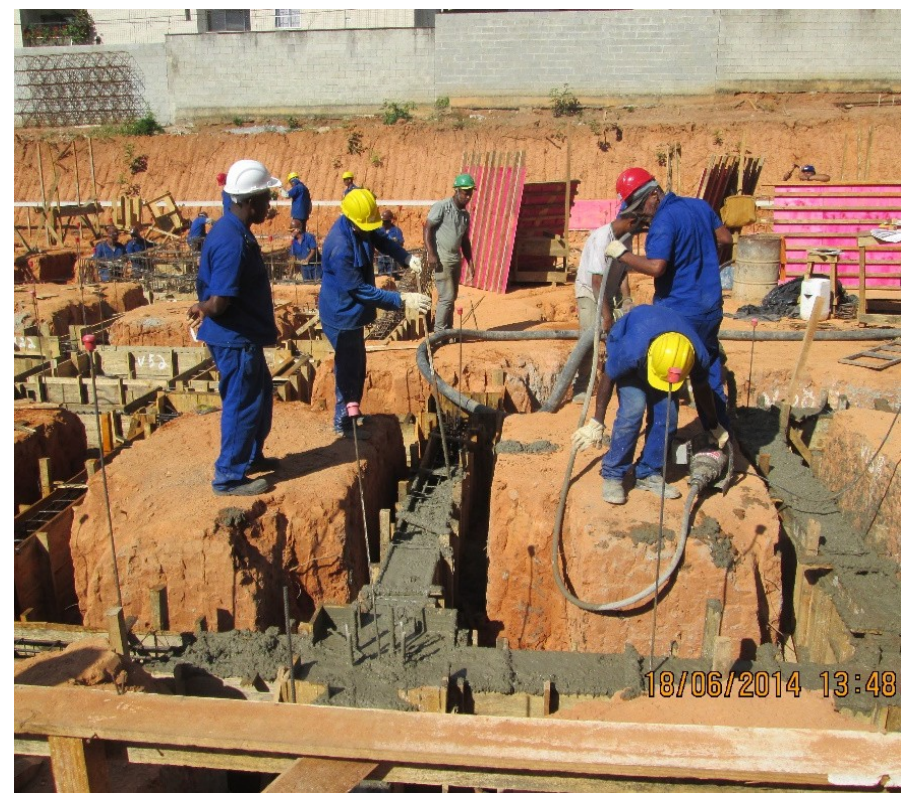

Fonte: Fornecida pela construtora, (2016).

O controle tecnológico do concreto foi realizado em conformidade com as normas NBR 5738 (ABNT, 2003) e NBR 5739 (ABNT, 2007). O método adotado para garantir a estanqueidade desse elemento construtivo foi a mistura de um aditivo impermeabilizante por cristalização integral no concreto. Esse aditivo consiste em uma mistura de cimento Portland, areia de sílica fina tratada e compostos químicos ativos. Esses compostos reagem com a umidade do concreto fresco e com os produtos da hidratação do cimento, formando uma estrutura cristalina insolúvel nos poros e capilares do concreto. Dessa maneira, o concreto se torna permanentemente selado contra a penetração de água ou de outros líquidos em qualquer direção. O concreto aditivado também é protegido da deterioração, devido aos agentes agressivos da atmosfera. $O$ fornecedor do produto possui a certificação ISO 9001:2008, do Sistema de Gestão da Qualidade (PENETRON, 2015). Destaca-se que não foi realizada a aferição da estanqueidade após a cura do concreto.

\section{Alvenaria Estrutural}

O principal elemento construtivo desse estudo é a alvenaria estrutural (Figura 6 - a e b) que foi executada no período de abril de 2014 a abril de 2015. Os blocos de concreto utilizados foram os de concreto, fornecidos pela empresa da cidade, que possui as certificações: Selo da Qualidade (Associação Brasileira de Cimento Portland - ABCP), Bloco Brasil (Associação Brasileira da Indústria de Blocos de Concreto), PBQP-H (Programa Brasileiro da Qualidade e Produtividade do Habitat) e Licença ambiental. A manutenção destas certificações, estimula a 
empresa na produção dos blocos em conformidade com as normas da ABNT, agregando valor aos produtos, garantindo maior segurança - por parte dos consumidores, e promovendo melhorias na relação do fornecedor com o cliente. O controle tecnológico dos blocos e prismas foi realizado em conformidade com a NBR 15961 (ABNT, 2011).

Figura 4- Execução da alvenaria estrutural (a) 1으 pavimento e (b) 2ㅇ pavimento.

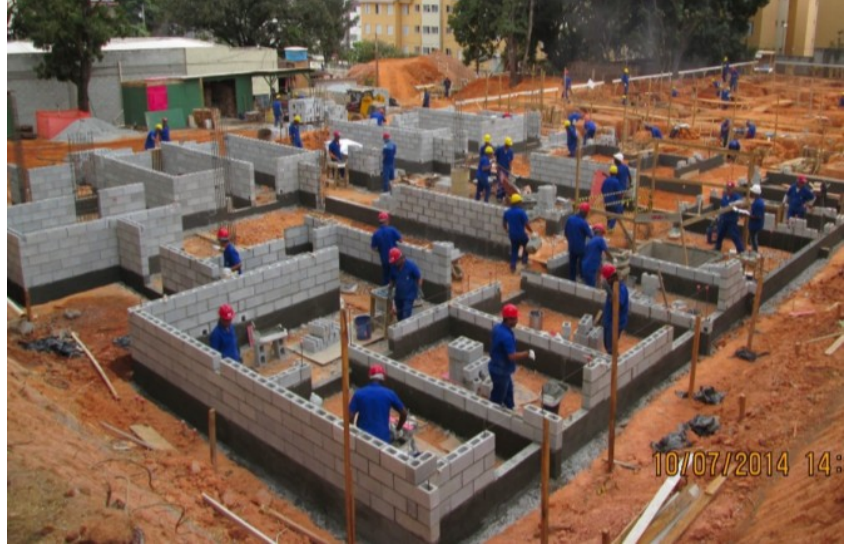

(a)

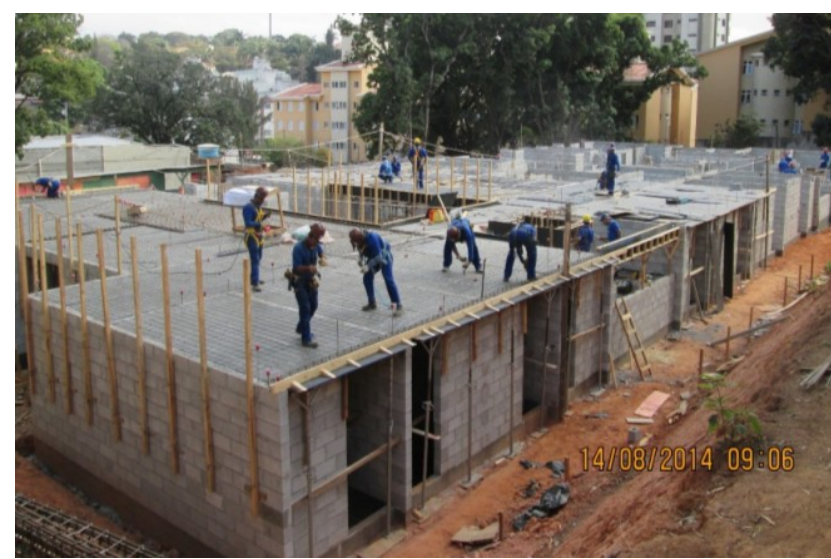

(b)

Fonte: Fornecida pela construtora, (2016).

A argamassa de assentamento utilizada foi a industrializada, que, de acordo com a NBR 13529 (ABNT, 2013). A utilização desse tipo de argamassa, em detrimento da preparada em obra, é sinônimo de racionalização na produção. Há ganhos potenciais em termos logísticos e organizacionais na operacionalização do canteiro, devido ao menor número de controles nos recebimentos, armazenagens e processamentos de materiais envolvidos (RIBAS; CARVALHO JÚNIOR, 2007). Foi previsto o assentamento da argamassa nas juntas verticais e horizontais, entretanto ocorreram adversidades com a mão de obra, que, devido a ajustes de erros na paginação, negligenciou algumas juntas verticais. Destaca-se que este procedimento pode comprometer a isolação acústica dos elementos de vedação da edificação, sendo necessário uma avaliação de campo neste sentido.

A dosagem do graute foi feita conforme NBR 8798 (ABNT, 1985), sendo o controle tecnológico desse elemento realizado em conformidade com as normas NBR 5738 (ABNT, 2003) e NBR 5739 (ABNT, 2007). O traço foi calculado através da consultoria de profissional especializado, sendo testado em laboratório anteriormente à sua utilização na obra. 
A execução do assentamento dos blocos foi realizada seguindo-se as recomendações dos projetos de paginação detalhados de cada parede, contudo foram encontradas divergências entre o projeto e a execução. Segundo a engenheira responsável, a maior parte dos problemas de execução da obra ocorreram nessa fase. Por se tratar de uma iniciativa público-privada, há níveis de burocracia que inviabilizaram a contratação de bloqueiros (pedreiros especializados no sistema construtivo em alvenaria estrutural), foram, portanto, contratados pedreiros aos quais não era exigida essa qualificação. Apesar da realização de treinamentos periódicos com a equipe, não foram alcançadas a qualidade de execução e a eficiência desejadas. Devido às adversidades citadas, houve atraso no cronograma de execução, e desalinhamento do prumo de algumas paredes.

\section{Concreto Armado}

Além da execução das lajes maciças (Figura 7) em todos os pavimentos, também foram construídos (no período de junho de 2014 a junho de 2015) elementos em concreto armado na área entre os prédios, onde constam em projeto, os espaços de convivência da moradia.

Figura 5- Montagem de uma das lajes.

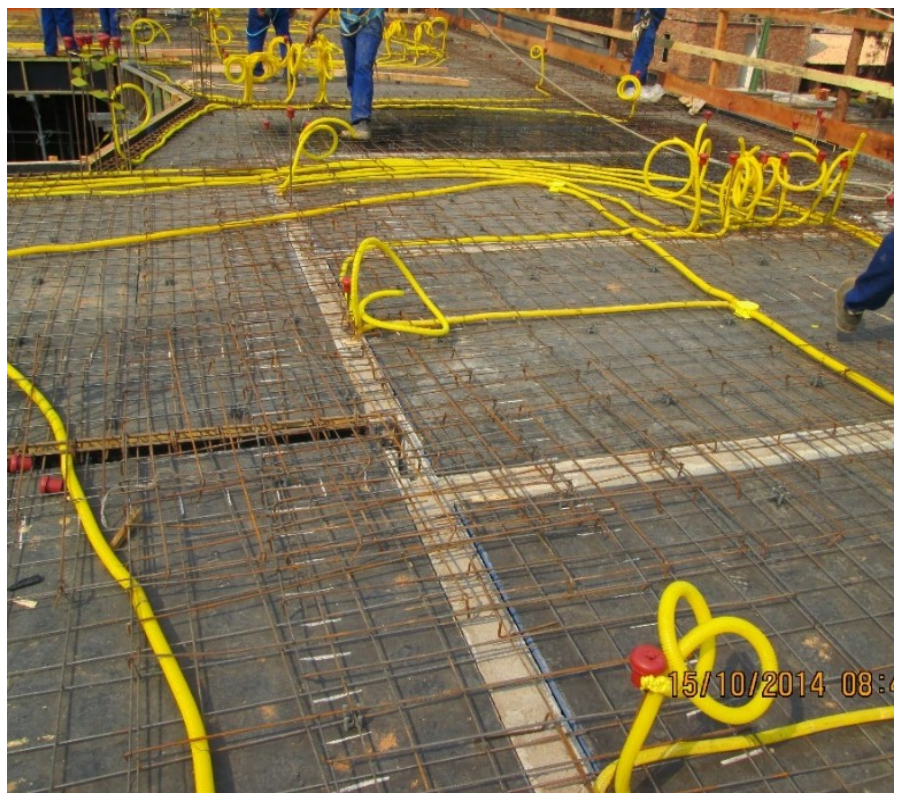

Fonte: Fornecida pela construtora, (2016).

O concreto utilizado foi o usinado, com resistência característica do concreto de $25 \mathrm{MPa}$, e foi feito controle tecnológico total por meio de um laboratório idôneo. Foram consultados todos os relatórios de ruptura dos corpos de prova, moldados e ensaiados em conformidade com as normas NBR 5738 (ABNT, 2003) e NBR 5739 (ABNT, 2007), sendo a maioria dos lotes aceito. Para os lotes não aprovados, a resistência foi muito próxima à esperada, e foi consultado o calculista responsável pelo projeto estrutural sobre a necessidade de reforços, mas não houve necessidade, devido aos fatores de segurança adotados.

O aço utilizado foi o CA-50 e o CA-60, fornecido por empresa certificada. O corte e a dobra das barras foram realizadas na obra, que contava com uma 
estação de trabalho exclusiva à essa atividade. Não houve nenhuma ocorrência adversa relacionada a esse elemento construtivo durante a execução do edifício.

\section{Verificação da Conformidade à NBR 15575-2}

Para que a estrutura atenda aos requisitos normativos, é preciso que seja previsto a não ocorrência de nenhum dos aspectos relacionados abaixo:

a) Não ruir ou perder a estabilidade de qualquer de suas partes.

b) Prover segurança aos usuários sob ação de impactos, choques, vibrações e outras solicitações decorrentes da utilização normal da edificação, previsíveis na época de projeto.

c) Não provocar sensação de insegurança aos usuários pelas deformações de quaisquer elementos da edificação, permitindo-se tal requisito atendido caso as deformações se mantenham dentro dos limites estabelecidos nesta Norma.

d) Não repercutir em estados inaceitáveis de fissura de vedação e acabamentos.

e) Não prejudicar a manobra normal de partes móveis, como portas e janelas, nem prejudicar o funcionamento normal das instalações em face das deformações dos elementos estruturais.

f) Atender às disposições da NBR 6122 (ABNT, 2010), relativas às interações com o solo e com o entorno da edificação.

Foi realizada inspeção visual na visita técnica à obra, e não foram detectadas ocorrências desfavoráveis. Os estados limites e o cálculo estrutural foram realizados à luz das NBR 8681 (ABNT, 2003), NBR 6118 (ABNT, 2014), NBR 6120 (ABNT, 1980), NBR 6122 (ABNT, 2010) e NBR 6123 (ABNT, 1988). O projeto estrutural contemplava as informações relativas à sobrecargas limitantes no uso das edificações no manual do proprietário, entretanto não havia previsão de elaboração do manual.

Foram realizados os ensaios pertinentes à verificação do desempenho estrutural dos elementos em concreto (blocos estruturais e concreto armado) conforme às prescrições normativas. Entretanto os ensaios de corpo mole e corpo duro, que garantem a estabilidade das estruturas submetidas a impactos durante a vida útil, descritos pela NBR 15575-2 (ABNT, 2013), não foram realizados.

\section{Considerações Acerca do Estudo}

Através da análise dos dados coletados na visita técnica, da entrevista realizada e da verificação dos documentos disponibilizados pela construtora, nota-se que houve a iniciativa de cumprimento dos requisitos normativos referentes a cada etapa de execução da edificação quanto às normas prescritivas da construção civil e isto culminou no atendimento de boa parte dos preceitos da norma de desempenho.

A NBR 15575 (ABNT, 2013) traz orientações para cada etapa construtiva realizada, assim como prevê requisitos mínimos quantitativos de desempenho a 
serem cumpridos no período da vida útil de projeto. É previsto pela norma o atendimento às exigências dos usuários ao longo dos anos, através da definição de responsabilidades de todos os envolvidos: projetistas, fornecedores de materiais, componentes e sistemas, construtor e usuário. Uma das principais inovações dessa norma, é dar suporte a utilizações de métodos construtivos inovadores, desde que sejam cumpridos, por esses sistemas, os parâmetros estabelecidos.

No presente estudo de caso foram utilizados sistemas construtivos tradicionais, para os quais já existem normas consolidadas embasadas em pesquisas que garantem a eficiência dos sistemas, quando executados corretamente. Os materiais utilizados seguem procedimentos de avaliação da qualidade, comprovados pela realização dos ensaios específicos ou pela exigência de certificados e relatórios de conformidade.

\section{Propostas}

Propõe-se aqui algumas sugestões de procedimentos necessários à comprovação do desempenho da edificação (a respeito dos itens analisados) que não foram realizados:

- Certificação e documentação completos dos laudos, projetos e diários de obras com todas as atividades desenvolvidas durante o empreendimento;

- Para os requisitos estruturais sugere-se a construção de um protótipo (parede-teste moldada na obra) para execução de ensaios destrutivos, tais como: ensaios de corpo mole e de corpo duro para elementos estruturais situados na fachada e no interior da edificação, conforme descritos no item 7.4 e nos anexos C e D da NBR 15575-2 (ABNT, 2013) e verificação das solicitações de cargas provenientes de peças suspensas atuantes nos sistemas de vedações internas e externas;

- Avaliar a estanqueidade dos componentes impermeabilizados, conforme a NBR 9575(ABNT, 2010);

- Determinar de resistência ao fogo, à luz da NBR 5628 (ABNT, 2002);

- Medir o isolamento acústico à luz, conforme NBR 10152 (ABNT, 1987);

- Contratação de mão de obra especializada no sistema construtivo adotado ou realizar treinamento e teste que comprovem habilidade para execução dos serviços;

- Utilização de plataformas BIM para produção e compatibilização dos projetos e previsão do ciclo de vida e planejamento eficiente do empreendimento;

- Realizar reuniões de avaliação crítica e de validação por parte das

empresas participantes do projeto;

- Desenvolver do manual de uso, operação e manutenção referencial, através da equipe de engenharia civil da obra. 
Tendo em vista as considerações realizadas, sobre as exigências da Norma de Desempenho (Partes 1 e 2), contrastadas com a construção de uma edificação, conforme às normas já existentes antes de sua implementação, percebe-se que grande parte do desempenho já era garantindo com o cumprimento das mesmas. As principais alterações no sistema construtivo após a vigência da NBR 15575 (ABNT, 2013), referem-se ao acréscimo de rigor no controle tecnológico dos elementos, no planejamento de sistemas construtivos através de características particulares desses elementos e na previsão da manutenabilidade da edificação. Tais filosofias já são seguidas em outras indústrias como a automobilística, de telefonia, entre outras.

O maior rigor no planejamento, controle e execução trazem como consequência a redução de desperdícios, retrabalho e insatisfação dos usuários, além de propiciar um caráter de maior sustentabilidade na indústria de construção civil.

No estudo de caso realizado foi evidenciado que, mesmo sem a obrigatoriedade de atendimento à Norma de Desempenho, e com condições desfavoráveis devido à empresa responsável pela obra não ter experiência em construção civil, ao orçamento restrito e às grandes burocracias atreladas à iniciativa pública, foi possível atender a muitos dos requisitos da norma. 0 empenho da equipe em executar os serviços conforme os parâmetros técnicos das normas brasileira e a busca por consultorias de empresas especializadas garantiram um produto final com características satisfatórias. A execução dos ensaios de caracterização dos elementos construtivos e a avaliação de produtos certificados no momento da compra se mostraram de extrema importância para esse fim.

\section{AGRADECIMENTOS}

Os autores agradecem a todos os colaboradores dessa pesquisa, especialmente à engenharia e coordenação da obra analisada, à UFMG, ao CEFET-MG, à FAPEMIG e à CAPES. 


\title{
Technical and managerial evaluation of the performance requirements of student housing construction
}

\begin{abstract}
This research explores the main needs for changes in the building process of structural masonry buildings, before and after the validity of NBR 15575, (2013). Developed the case study in a project of University Housing in Minas Gerais. Started the construction of the building before the validity of this norm, therefore its fulfillment would not apply, and however, carried out its execution in accordance with the requirements of other Brazilian standards applied to civil construction.. When analyzing the data collected during the technical visit carried out, the interviews with the technical manager and the verification of the documents made available by the company, it was verified that a large part of the regulatory requirements were fulfilled. Based on the information and items analyzed, made proposals for the necessary procedures to validate the performance level of the building. The present case study has shown that, even without meeting the standard performance, the adoption of other existing standards and efficient management of can satisfy many of its requirements: supplies, labor and procedures.
\end{abstract}

KEYWORDS: Brazilian Performance Standard. General Requirements. Structural Masonry. Planning and Management. 


\section{REFERÊNCIAS}

ABNT. NBR 6120 - Cargas para o cálculo de estruturas de edificações. Rio de JaneiroAssociação Brasileira de Normas Técnicas, 1980.

ABNT. NBR 10152 - Níveis de ruído para conforto acústico. Rio de JaneiroAssociação Brasileira de Normas Técnicas, 1987.

ABNT. NBR 6123 - Forças devido ao vento em edificações. Rio de JaneiroAssociação Brasileira de Normas Técnicas, 1988.

ABNT. NBR 12131 - Estacas - Prova de carga estática. Rio de JaneiroAssociação Brasileira de Normas Técnicas, 1992.

ABNT NBR 12722. Discriminação de serviços para construção de edifícios. Rio de Janeiro, 1992.

ABNT NBR 13529. Revestimento de paredes e tetos de argamassas inorgânicas - Terminologia. Rio de Janeiro, 2013.

ABNT. NBR 14037 - Manual de operação, uso e manutenção das edificações - Conteúdo e recomendações para elaboração e apresentação. Rio de Janeiro, 1998.

ABNT. NBR 5674 Manutenção de edificações - Procedimento. Rio de Janeiro, 1999.

ABNT. NBR 5628 - Componentes construtivos estruturais - Determinação da resistência ao fogo. Rio de Janeiro, 2002.

ABNT. NBR 5738 - Concreto - Procedimento para moldagem e cura de corpos de prova. Rio de Janeiro, 2003.

ABNT. NBR 8681 - Ações e segurança nas estruturas - Procedimento. Rio de Janeiro, 2003.

ABNT. NBR 9050 - Acessibilidade a edificações, mobiliário, espaços e equipamentos urbanos. Rio de Janeiro, 2004.

ABNT. NBR 5739 - Concreto - Ensaio de compressão de Corpos-de-prova cilíndricos. Rio de Janeiro, 2007. 
ABNT. NBR 9575 - Impermeabilização - Seleção e projeto. Rio de Janeiro, 2010.

ABNT. NBR 6122 - Projeto e execução de fundações. Rio de Janeiro, 2010.

ABNT. NBR 15961-2 - Alvenaria estrutural - Blocos de concreto - Parte 2: Execução e controle de obras. Rio de Janeiro, 2011.

ABNT. NBR 15575 - Edificações habitacionais - Desempenho. Rio de Janeiro, 2013.

ABNT. NBR 13529 - Revestimento de paredes e tetos de argamassas inorgânicas - Terminologia. Rio de Janeiro, 2013.

ABNT NBR 11578 - Cimento Portland composto. Rio de Janeiro, 1997.

ABNT NBR 12722 Discriminação de serviços para construção de edifícios Rio de JaneiroAssociação Brasileira de Cimento Portland, , 1992.

ABNT NBR 14037 - Manual de operação, uso e manutenção das edificações - Conteúdo e recomendações para elaboração e apresentação. Rio de Janeiro, 1998.

ABNT NBR 5674 - Manutenção de edificações - Procedimento. Rio de Janeiro, 1999.

ABNT NBR 6118 - Projeto de estruturas de concreto - Procedimento. Rio de Janeiro, 2014.

ABNT NBR 8044 - Projeto Geotécnico. Rio de Janeiro, 1983.

ABNT NBR 8798 - Execução e controle de obras em alvenaria estrutural de blocos vazados de concreto. Rio de Janeiro, 1985.

ARAÚJO, N. M. C. DE et al. IMPLANTAÇÃO DO PBQP-H EM EMPRESAS CONSTRUTORAS DE EDIFICAÇÕES VERTICAIS NA GRANDE JOÃO PESSOA : UM ESTUDO DE CASO. XXII Encontro Nacional de Engenharia de Produção. Anais. João Pessoa: ENGEP, 2002 
BARROS, J. V. P.; RÊGO, R. D. M. Estudo e avaliação de tecnologias Bim para projetação em arquitetura, engenharia e construção. Building, n. 1, 2010.

BLOCO SIGMA. Bloco Sigma - Certificações. Disponível em:

<http://www.blocosigma.com.br/empresa/>. Acesso em: 17 jun. 2016.

BRAMESHUBER, Wolfgang; SAENGER, Dorothea; WINKELS, Bernd. Recent developments in masonry construction / Neuere Entwicklungen im Mauerwerkbau. Mauerwerk, v. 18, p. 151-163, 2014. crossref

BRITO, Adriana C. et al. Contribuições para o aprimoramento da NBR 15.575 referente ao método simplificado de avaliação de desempenho térmico de edifícios. XIV Encontro Nacional de Tecnologia do Ambiente Construído, n. 1, p. 3191-3197, 2012.

CAVIERES, Andres; GENTRY, Russell; AL-HADDAD, Tristan. Knowledge-based parametric tools for concrete masonry walls: Conceptual design and preliminary structural analysis. Automation in Construction, v. 20, n. 6, p. 716-728, 2011. crossref

CERATTO, R. et al. Tecnologia de informação para monitorar requisitos de saúde e segurança de trabalho no sistema produtivo da construção civil. XXXVI Encontro Nacional de Engenharia de Produção. Anais.Curitiba: ENGEP, 2014.

CHIODINI, M. et al. Teste de integridade em estacas: pit - um ensaio não destrutivo. Encontro Científico Cultural Interinstitucional. Anais.Cascavel: FAG, 2013.

CINTRA, J. C. A. et al. Fundações: ensaios estáticos e dinâmicos. 1. ed. São Paulo: Oficina de textos, 2013.

CREMONA, Christian. Structural Performance: Probability-Based Assessment. 1. ed. London: Wiley-ISTE, 2011.

CRESPO, C. C.; RUSCHEL, R. C. Ferramentas BIM: um desafio para a melhoria no ciclo de vida do projeto. III Encontro de Tecnologia de Informação e Comunicação na Construção Civil. Anais...Porto Alegre: Integração de sistemas em Arquitetura, Engenharia e Construção, 2007.

FIGUEIREDO, Cássio Marcus Mory; SILVA, Matheus Pena da Silva e; FROTA, Consuelo Alves Da. Estudo de caso: edificação com fundações em estacas 
hélice contínua monitorada. Estudos Tecnológicos em Engenharia - Unisinos, v. 11, n. 1, p. $32-41,2015$

GARRIDO, Edleusa Nery; MERCURI, Elizabeth Nogueira Gomes da Silva. A moradia estudantil universitária como tema na produçaoo científica nacional. Associação Brasileira de Psicologia Escolar e Educacional, v. 17, n. 1, p. 87-95, 2013. crossref

GAVIN, K.; CADOGAN, D.; TWOMEY, L. Axial resistance of CFA piles in Dublin Boulder Clay. Proceedings of the ICE - Geotechnical Engineering, v. 161, n. 4, p. 171-180, 2008. crossref

HOL'KO, Michal; STACHO, Jakub. Comparison of Numerical Analyses with a Static Load Test of a Continuous Flight Auger Pile. Slovak Journal of Civil Engineering, v. 22, n. 4, p. 1-10, 2014. crossref

KERN, Andrea Parisi; SILVA, Adriana; KAZMIERCZAK, Claudio De Souza. O processo de implantação de normas de desempenho na construção: um comparativo entre a Espanha (CTE) e o Brasil (NBR 15575/2013). Gestão \& Tecnologia de Projetos, v. 9, n. 1, p. 89-101, 2014. crossref

LAIR, J.; CHEVALIER, J-L.; RILLING, J. Contribution from the CSTB 2001, Wellington: FMEA Research for and Application to the Building Domain, 2001. p. 41-50.

LOUZANO, Gil; SÁNCHEZ FILHO, Emil de Souza. Controle de Recepção de Bloco Cerâmico em Obras de Alvenaria Estrutural. Engenharia Estudo e Pesquisa, p. 15, 2012.

INMETRO. Portaria n. ${ }^{\circ}$ 50, 2013.

LUCCHINE, F. R.; GOMES, A. R. CONSTRUÇÃO CIVIL VISANDO A PREVENÇÃO NR18. Revista Interdisciplinar do Pnesamento Científico, v. 1, p. 45-59, 2015. crossref

MACHADO, Diego Willian Nascimento. Alvenaria Estrutural. 2010. $43 \mathrm{f}$. Universidade Federal de Santa Maria, 2010.

MEACHAM, B.; et al. Performance system model - a framework for describing the totality of building performance 2003, Westborough, Malaysia: Proceedings of the 4a International Conference on PerformanceBased Codes and Fire Safety Design Methods, 2003. p. 8-10. 
MEKSOL. GEOSERVICE GEOTECNIA E FUNDAÇÕES LTDA. Disponível em: <http://www.meksol.com.br/obras-recentes/>. Acesso em: 20 jun. 2016.

MELGAÇO, L. A. et al. Visão Prospectiva sobre a gestão operacional em construtoras certificadas no PBQP-H. I Conferência latino-americana de construção sustentável. Anais. São Paulo: claCS'04 ENTAC'04, 2004

NAWATE, PRISCILLA SAYURI. Moradia do estudante universitário. 2014. 74 f. Universidade Tecnológica Federal do Paraná, 2014. Disponível em: <http://repositorio.roca.utfpr.edu.br/jspui/handle/1/2986>.

OLIVEIRA, C. M. DE. Curva Abc Na Gestão De Estoque Resumo. III Encontro Científico e Simpósio de Educação Unisalesiano. Anais .Lins: Unisalesiano, 2011

PARSEKIAN, Guilherme Aris. Parâmetros de projeto de alvenaria estrutural com blocos de concreto. 1. ed. São Carlos: EduFSCar, 2012. v. 53.

PENETRON. Ficha Técnica do produto - Penetron Admix. Lorena Penetron, 2015.

PIUCCO, L. T. Estudos e dimensionamento das fundações de uma torre eólica. Universidade Federal de Santa Catarina, 2014.

POZO, H. Administração de recursos materiais e patrimoniais: uma abordagem logística. $6^{\circ}$ ed. São Paulo.

RIBAS, L. C.; CARVALHO JÚNIOR, A. N. DE. Ganhos no potencial produtivo através da substituição de argamassa de revestimento rodada em obra por industrializada em sacos. Encontro Nacional de Engenharia de Produção. Anais. Foz do Iguaçu: ENGEP, 2007

REIS, Antônio Tarcísio da Luz; LAY, Maria Cristina Dias. Estudo sobre a percepção da pobreza em Portugal - Algumas considerações e recomendações. Ambiente Construído, v. 10, n. 4, p. 99-119, 2010.

RIBAS, Leonardo Calcagno; CARVALHO JÚNIOR, Antônio Neves De. Ganhos no potencial produtivo através da substituição de argamassa de revestimento rodada em obra por industrializada em sacos. 2007, Foz do Iguaçu: ENGEP, 2007. p. 1-10. 
RODRIGUES, André Montes; OLIVEIRA, Cláudia Terezinha de Andrade. A aplicabilidade da abordagem do desempenho em projetos residenciais multifamiliares. 2009. 14-16 f. Universidade de São Paulo, 2009.

RONCON, A.; OLIVEIRA, M. L.; BELTRAME, I. Processos gerenciais de gestão de pessoas em empresas do setor da construção civil . Revista de Carreiras e Pessoas, p. 114-128, 2015.

RUSSO, Gianpiero. Experimental investigations and analysis on different pile load testing procedures. Acta Geotechnica, v. 8, n. 1, p. 17-31, 2012

SACCO, L. M.; SCHUAB, M. R.; SANTOS, W. J. Análise do sistema construtivo de alvenaria estrutural em blocos de concreto na construção de uma moradia universitária. $58^{\circ}$ Congresso Brasileiro do Concreto. Anais. Belo Horizonte: 2016

SILVA, C. O. Manual de Desempenho - Alvenaria com Blocos de Concreto. São Paulo. Associação Brasileira da Indústria de Blocos de Concreto, 2014.

SILVA, E. F. et al. Avaliação de risco ergonômico: pedreiro na construção civil. Journal of Engineering and Technology Innovation, v. 2, p. 77-94, 2014.

SILVA, F. P.; MENDONÇA, T. M. Custo da rotatividade de pessoal : um estudo de caso em uma empresa da construção civil na cidade de Rondonópolis-MT. IX Simpósio de excelência em Gestão e Tecnologia. Anais. Resende: SEGeT, 2012

SOLU. Parecer técnico parcial das fundações (geotécnico). Belo Horizonte, SOLU Engenharia e Consultoria LTDA., 2014.

TALON, Aurélie et al. Temporal Quantification Method of Degradation Scenarios Based on FMEA. 2005, Lyon: FMEA Research for and Application to the Buildin g Domain, 2005. p. 20-28.

WANG, Lihui et al. Collaborative conceptual design - state of the art and future trends. Computer-Aided Design, v. 34, n. 13, p. 981-996, 2002.

WITICOVSKI, L. C.; EMILIA, L.; GARCIA, M. The Bim utilization in the civil construction projects. IJIE - Iberoamerican Journal of Industrial Engineering, v. 55, n. 48, p. 19, 2009. 
Recebido: 24 mai 2017

Aprovado: 18 mar 2018

DOI: 10.3895/gi.v14n1.5927

Como citar:

SCHUAB, M. R.; SALLES, P. V.; SANTOS, W. J.; PEGUERO, S. N. J. Avaliação técnico-gerencial do cumprimento dos requisitos de desempenho de edificação habitacional para estudantes. R. Gest. Indust.,

Ponta Grossa v. 14, n. 1, p. 36-67, jan./mar. 2018. Disponível em

<https://periodicos.utfpr.edu.br/rgi>. Acesso em: XXX.

Correspondência:

Mariana Rezende Schuab

Av. Amazonas, 7675 - Nova Gameleira, Belo Horizonte, Brasil.

Direito autoral: Este artigo está licenciado sob os termos da Licença Creative Commons-Atribuição 4.0

Internacional.

(c) (1) 